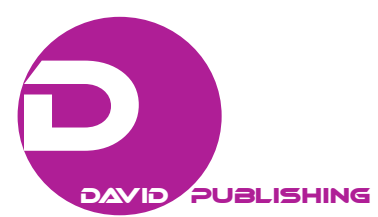

\title{
Problem Solving Skills of Secondary School Students
}

\author{
Belgin Bal İncebacak, Esen Ersoy \\ Ondokuz Mayis University, Samsun, Turkey
}

\begin{abstract}
A problem is a situation, in which a person tries to find a solution and does not exactly know how but still tries to solve it. One of the important elements of problem solving skills that individuals should have is to choose the appropriate strategy in the solution of the problems, which is important in terms of achieving success in solving problems. The research question of the study is "what are the levels of sixth and seventh grade students' problem solving skills?" The aim of this study was to investigate the problem solving and problem-solving strategies levels of secondary school students. The study was carried out through method with a total of 72 students from the two provinces in the Black Sea region of Turkey selected by random in the second term of the 2014-2015 academic year. In this qualitative research for the case study, content analysis was applied. The study group consists of 50 students in Samsun province and 22 students in Sinop province in the Blacksea region, 35 of the students are females, whereas 37 of them are male students. The methodology of the study is case study method, which is in accordance with the nature of qualitative research. In this qualitative research for the case study, content analysis was applied in order to evaluate the data. In the study, five creative problems developed by Smith, which were adapted into Turkish by the researchers, were used as the data collection tools. The problems applied were evaluated according to Polya's stage of problem solving. The problems were evaluated according to stages such as understanding the problem, choosing a strategy, applying the chosen strategy, and evaluating the solution. While examining students' problem solving papers, it was observed that they were more successful at solving problems, with which they came across before or are similar to the ones they had solved. It was observed that majority of the students had difficulty in solving non-routine problems. It is believed that this results from the fact that mostly routine problems are discussed and solved in the curricula.
\end{abstract}

Keywords: mathematics, problem, problem solving, problem solving stages, secondary school, Polya

\section{Outcome Predictions in Legal Decision Making}

Problem can be defined as a situation which makes a discomfort for the individuals that encounter with the situation. This kind of problematic discomfort leads individuals into imbalance and this ambiguous situation reaches balance only by a plausible, reasonable, and practical solution. In parallel with these descriptions, Dewey (1991) defined a problem as an ambiguity in an individual's mind while analyzing a problem or when they are faced with a situation. Problem is a situation that individuals may encounter anytime throughout their lives. It is important to learn the problem solving skill to overcome the problems encountered.

Belgin Bal İncebacak, research assistant, Faculty of Education, Department of Primary Mathematics Education, Ondokuz Mayis University, Samsun, Turkey.

Esen Ersoy, Ph.D., assistant professor, Faculty of Education, Department of Primary Mathematics Education, Ondokuz Mayis University, Samsun, Turkey.

Correspondence concerning this article should be addressed to Belgin Bal İncebacak, Department of Classroom Teaching, Faculty of Education, Ondokuz Mayis University, 55200, Kurupelit, Samsun, Turkey. 
From childhood to the old ages, individuals may face with many problematic situations in many levels and it is important to learn problem solving abilities. Problem solving can be related with many cognitive abilities also, ranging from logic, analysis, mathematics, and science (Aslan, 2002, p. 338). Hence, problem solving can simply be defined as offering a solution, an idea to a problematic situation. Problem solving abilities are important skills for educational area because a healthy society or a healthy nation can only maintain its existence through adopting themselves into new conditions by problem solving abilities. Problem solving skills are important for every field of life in order to lead a happy and healthy life. An important point here is that Kennedy (1980, p. 28) argued that problem solving is related to individuals' previous knowledge and experiences. Hence, internalization of problem solving skills is an important step for using them effectively. An individual will become more successful once he/she internalizes that behavior. MacGregor and Stacey (1996; 2000), stated that students could more easily apply the problem solving strategies they learned when they internalize the behavior of problem solving. They mentioned that solely mathematical calculation knowledge is not enough on its own while solving a problem, a specifically dominant type of knowledge which is defined as domain specific knowledge is also required. NCTM Standards (2000), emphasized that the questions asked to students should be based on the lives of students, challenge students to develop and apply strategies, not be easily solved, and enable students to form new knowledge by making use of their previous knowledge.

Problem solving usually refers to handling and evaluating problems, and arriving at a solution (Heppner \& Petersen, 1982). According to findings of recent researches, one of theimportant aspects of problem solving process is to differentiate the known from unknown (DeBellis \& Goldin, 1997; Goldin, 1988; 1998). Many researchers discussed that there is no solely one way to solve a problem. D'zurilla and Goldfried (1971) stated that the strategies people use while solving a problem are frequently based on their social environments, previous learnings, and personal characteristics; because A. E. Ivey, M. B. Ivey, and Simek-Morgan (1993) argued that individuals spend most of their time on solving and providing a conclusion to the problems they are faced with. To deal with how to solve a problem is an important asset for both formal and lifelong learning processes. This can be done with how to solve the steps of problem solution. Polya (1945) divided problem solving process into four stages: understanding the problem, determining the correct strategy for the problem, implementing the determined strategy, and evaluating the solution. Furthermore, problem solving strategies, include drawing a table or diagram, making a connection, systematically listing, writing an equation or in equation, benefitting from solutions to similar problems, assumption and checking, ratiocination, and assuming.

Verschaffel, De Corte, Lasure, Van Vaerenbergh, Boagerts, and Ratincky (1999) have determined strategies such as drawing; preparing a list, plan, or table; distinguishing between the relevant and irrelevant data; drawing a flow chart; assumption and testing; seeking a relation; using real life information; and simplifying the numbers. Examining the studies in the literature suggests the following.

Verschaffel and De Corte (1997) examined whether 10-11 years old students develop problem solving skills by using realist mathematical modeling or not. An experimental study was conducted with an experimental group and a control group. The papers on which every student solved each problematic situation were collected and analyzed according to qualitative analysis method. It was found out that 11 years old students were more successful since their high level thinking skills were more advanced.

Verschaffel et al. (1999) conducted a study to find out whether there may be a relationship among problem solving skills of fifth grade students if an experimental learning setting is provided. They received a 20 -hour 
training in total. The data were analyzed according to Polya's problem solving stages. It was determined that the training given is effective and students became more successful after the training.

Follmer (2000) carried out a study to discover the thinking processes while solving non-routine verbal problems. The study was conducted with 48 fourth grade elementary school students. The results suggested that the students became more successful when they realized how they solved the problem.

Asman and Markowitz (2001) conducted a study, which filled the application gap between what is taught at school and the real life. That study not only made students and teachers solve problems but also examined them based on problem solving stages. The results of the study demonstrated that teachers teach structured lessons through solving routine problems in text books, thus left the students with unrealistic problems which are quite boring.

Yazgan and Bintaş (2005) conducted a study, the aim of which was to examine the fourth and fifth grade students' learning and using of problem solving strategies. A pretest, posttest, and etention test were applied. Students in the control group attended their traditional courses. The findings of the study are as follows: 1) It was observed that fourth and fifth grade students can informally use problem solving strategies without any training; and 2) strategies can be learned by the fourth and fifth grade students and training had a positive effect on students' problem solving success.

Özsoy (2005) carried out a research with the purpose of determining the relation between fifth grade primary school students' mathematical achievement and problem solving skills. The study carried out on the 107 fifth grade students of two schools selected in Çankaya Region in Ankara, Turkey. Analyses have shown that there is a significant and positive relation between mathematical achievement and problem solving skills.

Y. Soylu and C. Soylu (2006) stated that problem solution is included not only among the aims of mathematics lessons; but also those of all others courses. Thirteen students were observed strictly for six weeks. Research data were obtained through the answers that students gave during the tests, and the interviews conducted with the subjects. According to the examination of the students' answer sheets and the results of the interviews, it was found that the students did not have difficulty in answering the exercises that required operational knowledge related to addition-subtraction-multiplication, whereas they had a difficulty in solving the problems that required conceptual and operational knowledge. Under the lights of the findings, there were some suggestions offered.

In the recent years, the outlook on mathematics education has changed. According to the previous outlook, mathematics education was about raising individuals, who knew and implemented mathematical rules (Y. Soylu \& C. Soylu, 2006, p. 101). This approach has started to change in the 21 st century and was replaced with constructivist education. The objective of education is raising individuals, who can apply the information they learn to solve problems, develop strategies, and transfer their knowledge. For that reason, it is important to determine how much of these skills that students actually possess. Once their level of solving these problems is determined, it will become easier to integrate such problems into the system of education.

Hence in this regard, it is thought to be an important subject to make a research on problem solving skills. Therefore, 72 students in sixth and seventh grades from two provinces in Black Sea region were selected based on simple random sampling to determine their level of problem solving skills.

\section{Problem Statement}

What is the level of problem solving skills in sixth and seventh grade students? 


\section{Research Design}

\section{Research Framework}

In this research, case study, which is one of the qualitative research patterns, was employed. Case study is a type of qualitative research pattern, which could be both the product and object of the research. Case study is the investigation of the reality and its relation with ongoing events and the situation existing in that environment (Creswell, 2013, pp. 96-97). Stake (1995) stated that there are three different methods for the analysis of case study. The first is instrumental case study, the second one is joint case study, and the third is internal case study. The one examined here is an instrumental case study, in which only one subject is focused on and examined in a limited area so as to be ensampled.

\section{Study Group}

The study was carried out with 72 students in total, from two provinces in the Black Sea region of Turkey during the second semester of the academic year of 2014-2015, by using random sampling method. Fifty students from Samsun province, and 22 students from Sinop province, consist of the study group.

\section{Data Collection Tool}

In this research, five problems prepared by Smith (1997) and translated into Turkish were used as the data collection tool. Last problem consists of two seperate problems.

Problemler (Figure 1):

(1) Smith (1997) "Shapes Within Shapes-1", p. 36;

(2) Smith (1997) "Shapes Within Shapes-2", p. 37;

(3) Smith (1997) "Unmagic Squares I", p. 22;

(4) Smith (1997) "Number Tracks-3", p. 13;

(5) Smith (1997) "Number Tracks-3", p. 13.

In the first problem of "Shapes Within Shapes-1", students are expected to find five triangles; 15 rectangles; eight triangles; 20 triangles; 51 rectangles; and 27 triangles.

In the second problem of "Shapes Within Shapes-2", students are expected to find left shape: equilateral triangles - 14; isosceles triangles - 24, Rt angled triangles - 72; regular hexagons - two; rectangles — nine; adet olduğunu, right shape, and equilateral triangles - 16; isosceles triangles - 24; Rt angled triangles-36; regular hexagons - three; and rectangles- 180.

In the third problem as "Unmagic Squares I", students are expected to find a solution that all the rows, columns, and both diagonals add up to 15 (Figure 2).

In the fourth problem of "Number Tracks-3", students are expected to find a solution that draws a line through any 20 numbers then add up the total. The line may not cross itself at any point. The line must not go through any number more than once. Only lines going across, up, or down are allowed. In this number track, all double digit numbers add up the total.

In the fifth problem of "Number Tracks-3", students are expected to find a solution that subtracts all single digit numbers.

\section{Data Analysis}

The students' papers were evaluated according to Polya's (1945) stages of understanding the problem, determining the strategy, implementing the determined strategy, and evaluating the results. 
Miles and Huberman (1994, p. 64) mentioned that the harmony level should equal to $80 \%$ in order to ensure reliability in qualitative studies and emphasized that Agreement Percentage Formula $P=\frac{N a \times 100}{N a+N d}$ should be applied so as to calculate it.

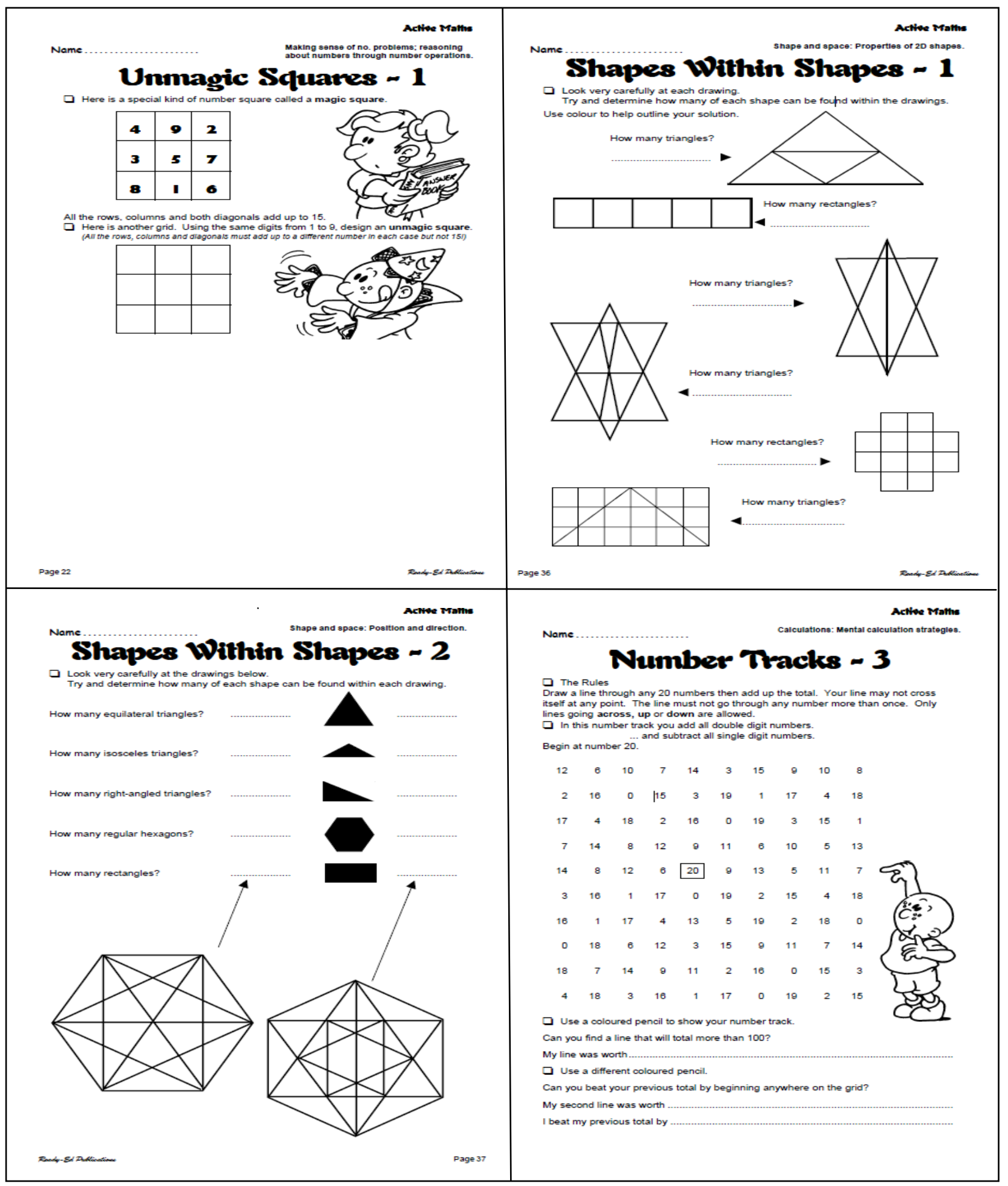

Figure 1. Problemler. 


\begin{tabular}{|lll|}
\hline 3 & 2 & 9 \\
6 & 1 & 4 \\
7 & 5 & 8 \\
\hline
\end{tabular}

Figure 2. "Unmagic Squares I": there are numerous answers and here is an example.

\section{Research Results and Analysis}

Results and Comments belong to the solution of the first problem.

\section{Understanding the Problem}

The results for the first phase of problem solving strategies were given in Table 1 below.

Table 1

The Evaluation of Understanding Problem by Two Researchers

\begin{tabular}{|c|c|c|c|c|}
\hline \multirow[t]{2}{*}{ Understanding the problem } & \multicolumn{2}{|c|}{ True } & \multicolumn{2}{|c|}{ False } \\
\hline & $f$ & $\%$ & $f$ & $\%$ \\
\hline 1. Problem & 45 & 63 & 27 & 37 \\
\hline 2. Problem & 15 & 21 & 57 & 79 \\
\hline 3. Problem & 68 & 94 & 4 & 6 \\
\hline 4. Problem & 10 & 14 & 62 & 86 \\
\hline 5. Problem & 5 & 7 & 67 & 93 \\
\hline
\end{tabular}

Examining the evaluations of two researchers for the first problem, the students did not have difficulty in the third question at the stage of understanding the problem and majority of them correctly understood the problem. It is also apparent that more than half of the students accurately understood the first problem. It is observed that the students incompletely understood the second and fourth problem. Especially in the fifth and last problem, students could not distinguish between what is given and what is expected in the problem. Understanding the problem is one of the essential points for the solution to the problem. Looking at it from this point of view, it is believed that students have a hard time in solving the problem since they cannot completely understand it.

\section{Determining Strategy}

Table 2 displays the data two researchers collected in the phase of determining strategy in the solution of the fifth problem.

Table 2

The Percentages and Frequencies of Strategy Determination

\begin{tabular}{llllllll}
\hline Determined strategies & 1. Problem & 2. Problem & 3. Problem & 4. Problem & 5. Problem & $f$ & $\%$ \\
\hline Rational reasoning & 0 & 0 & 58 & 0 & 0 & 58 & 7 \\
Assumption and checking & 35 & 35 & 55 & 68 & 9 & 202 & 25 \\
Assumption & 72 & 25 & 54 & 25 & 5 & 181 & 22 \\
Determined strategies & 72 & 63 & 68 & 65 & 24 & 292 & 36 \\
Establishing a connection & 35 & 5 & 2 & 0 & 0 & 42 & 5 \\
Not determining a strategy & 0 & 0 & 0 & 0 & 0 & 0 & 0 \\
Creating a table & 0 & 2 & 0 & 0 & 0 & 0 & 0 \\
Drawing a diagram & 0 & 6 & 0 & 5 & 34 & 45 & 5 \\
Writing an equation & 214 & 136 & 237 & 163 & 72 & 822 & 100 \\
Rational reasoning & 0 & 0 & 58 & 0 & 0 & 58 & 7 \\
\hline
\end{tabular}


In Table 2, it can be seen that students mostly use predicting the strategy for problem solutions. Firstly, they use prediction and control and they use logical reasoning skills in the third rank. The number of students in establishing a connection and the number of student not using stragies are the same. Stundents do not prefer to use diagrams and wirte equations can be seen in Table 2. The third problem is the problem that was mostly solved by predicting a strategy for solutions. Students at least use one strategy for this solution. Secondly, students use strategies for the first problem and because it has many sub problems they use more strategies. Similarly, students use at least one strategy for the fourth problem. As for the number of strategies they use, students use fewer strategies for the fifth problem. It can be seen that students have difficulties in this problem because of the trouble they face in the first phase of problem solving strategies.

\section{Application of Strategy}

The evaluation on the phase of applying the determined strategy is as follows:

Table 3

Evaluation of the Phase of Applying the Determined Strategy by Two Researchers

\begin{tabular}{lll}
\hline Application of strategy & $f$ & $\%$ \\
\hline 1. Problem & & 63 \\
\hline Correct strategy, correct solution & 27 & 37 \\
Correct strategy, incorrect solution & 0 & 0 \\
Incorrect strategy, correct solution & & 21 \\
\hline 2. Problem & 15 & 72 \\
\hline Correct strategy, correct solution & 51 & 7 \\
Correct strategy, incorrect solution & 6 & 94 \\
Incorrect strategy, correct solution & & 6 \\
\hline 3. Problem & 68 & 0 \\
\hline Correct strategy, correct solution & 4 & 14 \\
Correct strategy, incorrect solution & 0 & 76 \\
Incorrect strategy, correct solution & & 6 \\
\hline 4. Problem & 10 & \\
\hline Correct strategy, correct solution & 57 & 7 \\
Correct strategy, incorrect solution & 5 & 93 \\
Incorrect strategy, correct solution & & 0 \\
\hline 5. Problem & 5 & 67 \\
\hline Correct strategy, correct solution & 0 & \\
Correct strategy, incorrect solution & 5 & \\
Incorrect strategy, correct solution & 5 & \\
\hline
\end{tabular}

Examining Table 3, it is observed that $63 \%$ of the students were successful in the application of applying the chosen strategy for the first problem. These students picked the correct strategy and found the accurate solution. For the solution to the second problem, $21 \%$ of the students chose the correct strategy. However, even though, $72 \%$ of the students chose the correct strategy, they could not accurately solve the problem. When the third problem is considered, it was detected that $94 \%$ of the students successfully chose the correct strategy and found the accurate solution. For the fourth problem, 14\% of the students picked and applied the correct strategy; whereas $76 \%$ of them chose the correct strategy yet failed to obtain the correct solution. Moreover, it was found out that $6 \%$ of the students did not choose any strategies to solve the problem. Examining the fifth problem, it was observed that $93 \%$ of the students failed to apply the strategy they chose while solving the problem. 


\section{Evaluation of Solution}

Table 4 indicating the evaluation of solution posting application of the strategy is displayed below.

Table 4

Evaluation of the Phase of Evaluating the Solution by Two Researchers

\begin{tabular}{lll}
\hline Evaluation form of solution & $f$ & $\%$ \\
\hline 1. Problem & & 63 \\
\hline Correct evaluation & 45 & 37 \\
Incorrect evaluation & 27 & 21 \\
\hline 2. Problem & 15 & 72 \\
\hline Correct evaluation & 51 & 94 \\
Incorrect evaluation & & 6 \\
\hline 3. Problem & 68 & 14 \\
\hline Correct evaluation & 4 & 76 \\
\hline Incorrect evaluation & & 14 \\
\hline 4. Problem & 10 & 76 \\
\hline Correct evaluation & 57 & \\
\hline Incorrect evaluation & & 10 \\
\hline$\quad$ Croblem & 57 & \\
\hline Incorrect evaluation & & \\
\hline
\end{tabular}

Looking at Table 4 in terms of the way solutions were evaluated, it is apparent that $63 \%$ of the students were successful in the phase of evaluating the solution to the first problem. These students determined the correct strategy, obtained the accurate solution, and made sure that they reached the accurate solution, $21 \%$ of the students correctly evaluated the solution to the second problem. However, even though, $72 \%$ of the students chose the correct strategy, they could not accurately solve and evaluate the problem, $94 \%$ of the students were successful in the stage of evaluating the solution to the third problem. For the fourth problem, $14 \%$ of the students chose, applied, and accurately evaluated the correct strategy, $76 \%$ of them chose the correct strategy yet failed to obtain the correct solution, thus they could not correctly evaluate it. Examining the fifth problem, $93 \%$ of the students failed to correctly evaluate the problem due to the errors they made in the stage of understanding the problem.

\section{Discussion and Conclusion}

In the first problem called "shapes within shapes", it is observed that $63 \%$ of the students correctly understood the problem thus determined and applied the correct strategy and accurately evaluated it. Since this problem consists of more than one question, the students failed when they tried to solve every phase of that problem by using the same strategy. For this problem, students were expected to look at the shape through an integrative and elaborated approach to see the details. Even though $37 \%$ of the students correctly answered to the first two questions, they had a hard time in solving the next question since the shapes in these questions were complex and required more concentration. Therefore, the rate of those who correctly answered each question decreased. The first question had the highest rate of correct answers. Those who answered this question incorrectly are the students who could not focus on the bigger shape - the big triangle, thus counted the number of triangles one fewer. The same difficulty was also observed at the third and fourth phases of the 
problem. In the second phase of the problem, they experienced the same trouble they experienced in the first problem. The students rather focused on the big rectangle. It was detected that the students who incorrectly answered the questions counted the rectangles by looking at it from either right side or left side, instead of looking at it from both right and left side. In the fifth stage of the problem, the rate of correct answers given by the students is higher. In the last stage, it was observed that the students focused on inside the triangle and disregarded the triangles on the outside.

As for Figure 1, 63\% of students understand the first problem correctly and choose the right strategy and find the right solution and evaluate it correctly. The first problem has many sub problems therefore students must use more than one strategy. Although $37 \%$ of students find a correct solution to the first problem, as the shapes are complicated they have difficulties in subsequent solutions, hence the number of correct solutions decreased as well. The students mostly making mistakes are the ones who do not focus on the bigger triangle. The similar mistake can be seen in the second, third, and fourth phases, too. Students focus on the one side of shape in the second phase, hereby they count the shapes from one perspective. In the first phase of problem, there is a high percentage of finding the true value however as for the last phase they focus on the inside of the biggest triangle and do not focus on other triangles.

In the second problem called "shapes within shapes II", the students were presented with two separate images and asked to distinguish geometrical shapes within these images. At this stage, only $21 \%$ of the students succeeded. The reason why this rate decreased is that this problem consisted of more than one problem. Thereby the number of students, who correctly answered each question, decreased. Examining the problem stage by stage, the students had the highest rate at correctly finding equilateral triangle, isosceles triangle, and right triangle. The stage, at which students mostly failed, was finding the rectangle from the firstly given image. At this stage, the majority of students stated that there were no rectangles in the given image. They also mentioned that there was at least one rectangle in the second image.

In the second problem, students are asked to discern the shapes in two different images. Only $21 \%$ of students are successful in this problem because of many sub-questions in the problem resulting in decrease in the number of students finding correct answer. The analysis suggests that the students had the highest success rate in finding the equilateral triangle, isosceles triangle, and upright triangle. Students mostly make mistakes especially in finding the bigger rectangular in Figure 1. Most of them stated that there is no rectangular in the shape and there is at least one rectangular in second shape.

As for the unmagic square problem, students have few difficulties in solving it because it is thought that they have encountered this kind of problems in newspaper and games in Android phones and they are more prone to solve them correctly. This question had the highest rate in terms of being correctly answered. The fact that this question required students to add numbers, which is similar to those of the routine problems they solved, made it easier for the students to solve the problem.

In the fourth problem, students should follow the even numbers and they do it from up to bottom properly. In this problem, all students find the right strategy but they make mistakes in summation and also in choosing the right even numbers. Moreover, although some of them follow the right path from top to bottom and do summation correctly, they make mistakes for choosing the bigger or smaller numbers correctly and hence they can not take 100 points. In short, they failed to solve the problem. It was observed that the students thought in a monotonous manner and had difficulty in solving problems, which required them to think of more than one option at once. 
In fifth problem, only $7 \%$ of students correctly solve the problem. They have difficulties in choosing the right number properly. They also could not follow the right path and half of them left this question unanswered. It can be interpreted that students are not qualified in high order thinking skills hence they could not answer especially second, fourth, and fifth.

The secondary school students in the study group lacked of high level thinking skills, hence they had difficulty in solving the fourth and fifth problems, which required high level thinking. The skill of high level thinking requires focusing on more than one thing. It was observed that the students could not proceed by correlatively thinking of more than one event or possibility at once.

In conclusion, examining the problem solving stages of students for all of these five problems, it is observed that they correctly understood and did not have difficulty in solving the problems, which were similar to or same as the problems they had previously solved. Even though they correctly distinguished between what was given and what was asked in the problems, sometimes they failed to use the information given to them in the next stage of the problem. It was also detected that students chose the right strategies at the stage of determining the strategy for the problem, yet they had difficulty in applying the strategy they chose. Considering these facts, it is believed that if different types of problems are added to the curricula and students come across with these different kinds of problems, it will become easier for students to understand and solve these problems. It is also observed that when the students are faced with different types of problems, they had trouble with even applying the strategies they already knew. Some studies in the literature such as those of Ersoy and Güner (2014); Verschaffel et al. (1999); Anzai and Yokoyoma (1984) asserted that problem solving skills are learnable. Accordingly, it is possible to assert that the difficulty experienced at these stages can be overcome if students are provided with convenient learning environments and enabled to solve such problems. The studies of Y. Soylu and C. Soylu (2006), Özsoy (2005), and Yazgan and Bintaş (2005) found out that students succeed when they solve questions related to problem solving, which does not only contribute to success at mathematics but also helps obtain skills that are required in today's world.

To sum up, as the results of the analysis of five problems are investigated, students are more prone to solve correctly problems that they are accustomed to. Even though they can differentiate and understand problems, they could not use what they have properly. In problem solution phases, students choose the right strategies but they have sometimes difficulties in applying them correctly. Hence, it can be said that if students encounter with those kind of problem types more in accordance with new curriculum, they can easily solve those types of problems. Students are facing with difficulties when they confront with different problems as seen in the analysis. The previous studies in literature such as those of Ersoy and Güner (2014); Verschaffel et al. (1999); and Azai and Yokoyama (1984) state that problem solving skill can be learned. According to this, it is possible to say that if students are provided with convenient learning environments and enabled to solve such problems; the problems faced could be overcome.

\section{References}

Anzai, Y., \& Yokoyoma, T. (1984). Internal models in physics problem solving. Cognition and Instruction, 1(4), 397-450.

Aslan, E. A. (Ed.). (2002). Örgütte kişisel gelişim. Ankara: Nobel Yayıncilik.

Asman, D., \& Markowitz, Z. (2001). The use of real word knowledge in solving mathematical problems. Proceedings of the 25th

Conference of the International Group for the Psychology of Mathematics Education (Vol. 2, pp. 65-72). Netherlands: Utrecht University.

Creswell, J. W. (2013). Nitel araştirma yöntemleri. In M. Bütün and S. B. Demir, Çev. (Eds.). İstanbul: Siyasal Kitapevi. 
D'Zurilla, T. J., \& Goldfried, M. R. (1971). Problem solving and behavior modification. Journal of Abnormal Psychology, 78, 197-226.

DeBellis, V. A., \& Goldin, G. A. (1997). The affective domain in mathematical problem solving. In E. Pchkoncn (Ed.). Proceedings of the 21st Annual Conference of PME (Vol. 2, pp. 209-216). Helsinki, Finland: University of Helsinki Dept. of Teacher Education.

Dewey, J. (1991). How we think. New York: Prometheus Books, Buffalo.

Ersoy, E., \& Güner, P. (2014). Matematik öğretimi ve matematiksel düşünme. Eğitim ve Öğretim Araştırmaları Dergisi, 3(2), 102-112.

Follmer, R. (2000). Reading, mathematics and problem solving: The effects of direct instruction in the development of fourth grade students' strategic reading and problem solving approaches to textbased, nonroutine mathematics problems (unpublished Ph.D. thesis). Widener University, Chester, Pennsylvania.

Goldin, G. A. (1988). Affeclive representation anil mathematical problem solving. In M. J. Behr, C. B. Lacampagne, and M. M. Wheeler (Eds.). Proceedings of ilie lutti annual meeting of PME-NA (pp. 1-7). DeKalb, IL: Northern Illinois Univ. Department of Mathematics.

Goldin, G. A. (1998). Representational systems, learning, and problem solving in mathematics. Journal of Mathematical Behavior, 17(2), 137-165.

Heppner, P. P., \& Petersen, C. H. (1982). The development and implications of a personal problem solving inventiory. Journal of Counselling Psychology, 29, 66-75.

Ivey, A. E., Ivey, M. B., \& Simek-Morgan, L. (1993). Counseling and psychotherapy: A multicultural perspective. Boston: Allyn \& Bacon.

Kennedy, L. M. V. (1980). Educational psychology: In theory and practice. New York: Random House.

MacGregor, M., \& Stacey, K. (1996). Learning to formulate equations for problems. PME 20, July 8-12, Valencia, Spain, 3, 289-303.

Miles, M. B., \& Huberman, A. M. (1994). Qualitative data analysis: A sourcebook of new methods (2nd ed.). Thousand Oaks, CA: Sage.

National Council of Teachers of Mathematics (NCTM). (2000). Principles and standards for school mathematics. Reston, VA.

Özsoy, G. (2005). The relationship between problem solving skills and mathematical achievement. G̈̈, Gazi Eğitim Fakültesi Dergisi, 25(3), 179-190.

Polya, G. (1945). How to solve it. Princeton NJ: Princeton U. Press.

Smith, K. (1997). Activi maths problem solving maths for 10-12 years old students. Australia: Greenwood Perth.

Soylu, Y., \& Soylu, C. (2006). Matematik derslerinde başariya giden yolda problem çözmenin rolü. İnönü Üniversitesi Eğitim Fakültesi Dergisi, 7(11), 97-111.

Stacey, K., \& MacGregor, M. (2000). Learning the algebraic method of solving problems. Journal of Mathematıcal Behavir, $18(2), 149-167$.

Stake, R. (1995). The art of case study research. Thousand Oaks, CA: Sage.

Verschaffel, L., \& De Corte, E. (1997). Teaching realistic mathematical modeling in the elementary school: A teaching experiment with fifth graders. Journal for Research in Mathematics Education, 28, 577-601.

Verschaffel, L., De Corte, E., Lasure, S., Van Vaerenbergh, G., Boagerts, H., \& Ratincky, E. (1999). Learning to solve mathematical application problems: A design experiment with fifth graders. Mathematical Thinking \& Learning, 1(3), 195-229.

Yazgan, Y., \& Bintaş, J. (2005). Fourth and fifth grade students' levels of using problem solving strategies: A teaching experiment. Hacettepe Üniversitesi Egitim Fakültesi Dergisi, 28, 210-218. 